\title{
Use of cultured epithelial cells, including keratinocytes, for the detection of antinuclear antibodies
}

\author{
IRENE LEIGH, ${ }^{1}$ FENELLA WOJNAROWSKA ${ }^{2}$ SUSAN BURGE, \\ B BHOGAL, ${ }^{3}$ AND T $\mathrm{ZHU}^{1}$
}

From the ${ }^{1}$ Department of Dermatology, The London Hospital, London; ${ }^{2}$ Slade Hospital, Oxford; and ${ }^{3}$ St John's Hospital for Diseases of Skin, Lisle Street, London

SUMMARY The use of cultured human epithelial cells as a substrate for the detection of antinuclear antibodies (ANAs) improves the sensitivity of detection above the standard substrates used. Standard antisera have been screened against a series of epithelial cell lines, including keratinocytes. Selected cells have then been used to detect ANAs in 78 patients with discoid lupus erythematosus.

Key words: discoid lupus erythematosus.

Antinuclear antibodies (ANAs) are routinely detected by the indirect immunofluorescent staining of sections of animal tissues, commonly rodent liver. The detection of ANAs and their titre and pattern depend on the substrate used. ${ }^{1}$ Human cell lines show greater sensitivity than standard substrates and in addition different patterns of ANA staining can be detected, such as anticentromere and anticentriolar patterns, in patients with scleroderma. ${ }^{23}$ We have therefore screened standard sera ${ }^{4}$ with defined patterns of ANA reactivity on mouse liver against a number of epithelial cell lines and identified those giving greatest sensitivity and reproducibility. Keratinocytes appear to be a target for ANA binding in cutaneous lupus erythematosus, ${ }^{5}$ and as it is now possible to culture normal human keratinocytes $^{6}$ these were included in the series of cells tested.

ANAs are detected with conventional substrates in only $20-30 \%$ of patients with discoid lupus erythematosus (DLE). ${ }^{7}$ We have screened sera from patients with DLE diagnosed by clinical, histological, and immunocytochemical criteria, on the selected cell lines to determine whether the use of these substrates increases the detection of ANAs in DLE.

Accepted for publication 18 May 1987

Correspondence to Dr Irene Leigh, Department of Dermatology, The London Hospital, London E1 $1 \mathrm{BB}$.

\section{Materials and methods}

CELL CULTURE SYSTEMS

Normal human keratinocytes were prepared as a single cell suspension by treatment of keratotomed adult breast skin (from breast reductions) with $0.25 \%$ trypsin at $37^{\circ} \mathrm{C}$ for two to three hours. The cells were seeded into $5 \mathrm{~cm}$ dishes at a density of $10000 / \mathrm{cm}^{2}$ in the presence of a feeder layer of irradiated 3T3 cells using the medium described by Wu et al. ${ }^{8}$ The cells formed confluent cultures two to three weeks after seeding and were fixed in methanol: acetone $(1: 1)$ for five minutes.

The cell lines (see Table 1) were cultured on multiwell slides using Dulbecco's minimal essential medium and $10 \%$ fetal calf serum and fixed in methanol:acetone 1:1. All samples were stored in

Table 1 Origin of cell lines

\begin{tabular}{|c|c|}
\hline Cell line & Origin of cell line \\
\hline $\begin{array}{l}\text { SVK14 } \\
\text { HEp } \\
\text { TR146 } \\
\text { CAMA1 } \\
\text { T47D } \\
\text { MDA157 } \\
\text { PsF1 } \\
\text { BEK }\end{array}$ & $\begin{array}{l}\text { SV40 transformed keratinocytes } \\
\text { Laryngeal carcinoma line } \\
\text { Human squamous cell carcinoma line }{ }^{18} \\
\text { Human breast carcinoma line }{ }^{19} \\
\text { Psoriatic fibroblasts derived from skin biopsies } \\
\text { of involved skin } \\
\text { Bovine embryonal kidney }\end{array}$ \\
\hline
\end{tabular}


Table 2 Standard sera (A): highest titre detected on each substrate

\begin{tabular}{|c|c|c|c|c|c|}
\hline \multirow[t]{2}{*}{ Cell line } & \multicolumn{5}{|c|}{ Standard sera* (group A) } \\
\hline & Diffuse & Speckled & Peripheral & Nucleolar & Thready \\
\hline $\mathrm{HEp}_{2}$ & $1 / 2560$ & $>1 / 10240$ & $1 / 40$ & $>1 / 10240$ & $1 / 160$ \\
\hline $\mathrm{CK} \dagger$ & $1 / 320$ & $1 / 320$ & $1 / 40$ & $1 / 80$ & $1 / 40$ \\
\hline SvK14 & $1 / 2560$ & $1 / 2560$ & $1 / 320$ & $>1 / 10240$ & $1 / 640$ \\
\hline TR146 & $1 / 160$ & $1 / 320$ & $1 / 80$ & $>1 / 10240$ & $1 / 320$ \\
\hline CAMA1 & $1 / 10240$ & $1 / 2560$ & $1 / 320$ & $1 / 320$ & $1 / 320$ \\
\hline T47D & $1 / 10240$ & $1 / 10240$ & $1 / 10240$ & $1 / 10240$ & $1 / 640$ \\
\hline MDA157 & $1 / 10240$ & $1 / 10240$ & $1 / 80$ & $>1 / 10240$ & $1 / 640$ \\
\hline PsF1 & $1 / 640$ & $1 / 2560$ & $1 / 80$ & $>1 / 10240$ & $1 / 320$ \\
\hline BEK & $1 / 640$ & $1 / 2560$ & $1 / 40$ & $>1 / 10240$ & $1 / 320$ \\
\hline
\end{tabular}

${ }^{*}$ Kind gift of Dr Burnham.

†CK $=$ cultured keratinocytes

liquid nitrogen until used. Indirect immunofluorescence staining was performed using standard techniques with fluorescein isothiocyanate labelled goat antihuman IgG and IgM (DAKO).

\section{S T A N D A R D S E RA}

Group A. Five standard sera (kind gift of $\mathrm{Dr}$ Burnham) were used against all cell lines in dilutions from 1 in 4 to 1 in 20560 . They had shown a defined pattern of reactivity on mouse liver or spleen imprint that was diffuse (D), speckled (S), peripheral $(\mathrm{P})$, nucleolar $(\mathrm{N})$, or thready $(\mathrm{T})$.

Group B. Substrates were also tested with standard antisera to diffuse, speckled, and nucleolar patterns kindly provided by the CDC, Atlanta.

\section{TEST SERA}

Serum samples were tested from 78 patients with discoid lupus erythematosus diagnosed by clinical, histopathological, and immunopathological criteria. These patients therefore had chronic cutaneous lesions but no systemic manifestations of lupus erythematosus, no increased DNA binding capacity, and no extractable nuclear antigen reaction. No patients were receiving systemic treatment, apart from six who were receiving mepacrine. Clinical features were analysed according to the presence of photosensitivity, Raynaud's phenomenon, chilblains, and skin type. ${ }^{8}$ These data will form the basis of a separate report (S Mayou). Sera from 30 controls (healthy blood donors aged 18-65) were also studied. The results were assessed according to the presence of antinuclear antibodies and their titre and the pattern of staining, using the terminology of Burnham. ${ }^{9}$ Samples were read blind by the same observers (TZ, SB). Each sample was tested repeatedly; the pattern of staining was consistent, although where the titre varied, the mean value was taken.

\section{Results}

All the human cell lines demonstrated the ANAs of $\stackrel{ }{ }$ the standard sera, but the titres and patterns 0 obtained were dependent on the substrate used.

VARIATION IN TITRE

The titre of ANAs obtained using the reference antisera varied with the substrate as shown in Tabe $\overrightarrow{0}$ 2. There was a fourfold to 256 -fold variation in titre. of the individual antisera with different substrate (Table 2). The greatest titre variation was seen with peripheral and nucleolar antibodies. T47D was the most sensitive for the peripheral pattern of ANAs. The sensitivity of the other cell lines was similar in $\mathbb{Q}$ many cases to that of $\mathrm{HEp}_{2}$ cells. Interestingly, $\overrightarrow{\vec{A}}$ cultured keratinocytes provided a less sensitive $\frac{0}{3}$ substrate than most of the keratinocyte derived $\supset$ lines, even the closely related SvK14 cells (Table 3).

\section{VARIATION IN PATTERN}

The pattern of ANAs also varied with the substrate (Table 3). The diversity of pattern found in the diffuse ANA group probably reflected increased sensitivity of the cultured cells at high dilution, which allowed the visualisation of other antibodies 은 normally masked by the diffuse staining. This was seen with both sets of standard sera (Tables 4 and 5). In the American standard reference sera N

Table 3 Standard sera $(A)$ : variation in titre of $A N A$ with substrate

\begin{tabular}{llll}
\hline Pattern & Lowest titre & Highest titre \\
\hline Diffuse & 160 & 10240 \\
Speckled & 320 & 10240 \\
Peripheral & 40 & 10240 \\
Nucleolar & 80 & 10240 & \\
Thready & 40 & 640 &
\end{tabular}


Table 4 Standard sera $(A)$ : variation in pattern of ANAs with substrate

\begin{tabular}{|c|c|c|c|c|c|}
\hline \multirow[t]{2}{*}{ Cell line } & \multicolumn{5}{|c|}{ Standard sera-patterns detected } \\
\hline & Diffuse & Speckled & Peripheral & Nucleolar & Thready \\
\hline $\mathrm{HEp}_{2}$ & $\mathrm{D} / \mathrm{S} / \mathrm{P}$ & $\mathrm{S} / \mathrm{P} / \mathrm{T}$ & $\mathbf{P}$ & N/S & $T / P / S$ \\
\hline CK & $\mathrm{D} /-\mathrm{P}$ & S/D & P/D & $\mathbf{N}$ & Not done \\
\hline SvK14 & $\mathrm{D} / \mathrm{S} / \mathrm{P}$ & $\mathbf{S} / \mathbf{P}$ & P/D & $\mathrm{N}$ & $\mathrm{T} / \mathrm{S}$ \\
\hline TR146 & $\mathrm{D} / \mathrm{S} / \mathrm{P}$ & S/P & $P$ & $\mathbf{N}$ & $T / S$ \\
\hline CAMA1 & $-/ \mathrm{S} / \mathrm{P}$ & S/D & $\mathbf{P}$ & $\mathbf{N}$ & $T / \mathbf{P}$ \\
\hline T47D & $\mathrm{D} / \mathrm{S} / \mathrm{P}$ & $\mathrm{S} / \mathrm{D} / \mathrm{P}$ & $\mathbf{P}$ & $\mathbf{N}$ & $\mathrm{T}$ \\
\hline MDA157 & $-1 S$ & $\mathbf{S} / \mathbf{P}$ & $\mathrm{P} / \mathrm{D}$ & $\mathbf{N}$ & $\mathrm{T}$ \\
\hline PsF1 & $\mathrm{D} / \mathrm{S} / \mathrm{P}$ & $\mathbf{S}$ & $\mathrm{P} / \mathrm{D}$ & $\mathbf{N}$ & $\mathrm{T}$ \\
\hline BEK & $-P$ & $\mathbf{S} / \mathbf{P}$ & $\mathbf{P}$ & $\mathbf{N}$ & $\mathrm{T}$ \\
\hline
\end{tabular}

(group B) a distinct shift in pattern of diffuse staining was seen on dilution to peripheral staining (Table 5). Although most substrates recognised the expected pattern, multiple patterns were often seen,

Table 5 Standard sera group $B$-American national reference sera: variation in pattern with substrate on dilution

\begin{tabular}{lllll}
\hline Cell line & $\mathrm{HEp}_{2}$ & $\mathrm{TR} 146$ & $\mathrm{SvK14}$ & $\mathrm{CK}$ \\
\hline Diffuse & $\mathrm{D}$ & $\mathrm{D}$ & $\mathrm{D}$ & $\mathrm{D}$ \\
on dilution & $\mathrm{P}$ & $\mathrm{P}$ & $\mathrm{P}$ & $\mathrm{P}$ \\
Speckled & $\mathrm{S}$ & $\mathrm{S}$ & $\mathrm{S}$ & $\mathrm{S}$ \\
Nucleolar & $\mathrm{N}$ & $\mathrm{N}$ & $\mathrm{N}$ & $\mathrm{N}$ \\
\hline
\end{tabular}

Table 6 Patterns of ANAs in 78 patients with DLE

\begin{tabular}{lr}
\hline Pattern & No (\%) \\
\hline Speckled & $37(47)$ \\
Peripheral & $15(19)$ \\
Diffuse & $8(10)$ \\
Thready & $9(11)$ \\
Nucleolar & $3(4)$ \\
\hline
\end{tabular}

Table 7 ANA detection in DLE is substrate dependent

\begin{tabular}{lc}
\hline Substrate & $\begin{array}{l}\text { No of positive } \\
\text { sera }(\%)\end{array}$ \\
\hline All substrates & $42(54)$ \\
Mouse liver & $16(20)$ \\
All cell lines & $39(50)$ \\
& \\
Cell lines-additional positives & \\
HEp-total positives & $35(45)$ \\
HEp & 7 -alone \\
T47D-total positives & $7(9)$ \\
T47D-alone & $29(37)$ \\
Keratinocytes-total positives & $2(3)$ \\
Keratinocytes-alone & $17(22)$ \\
\hline
\end{tabular}

particularly in the diffuse and speckled group (A sera). The patterns were characterised according to the system of Burnham ${ }^{9}$ and are shown in the figures against SvK14 cells as this has not previously been published as a substrate for ANA testing (Fig. 1).

DETECTION OF ANAS IN SERA OF PATIENTS WITH DLE (Tables 6 and 7)

T47D cells were selected because of their sensitivity for peripheral antibodies and $\mathrm{HEp}_{2}$ cells as these are the most commonly used. Cultured keratinocytes and sections of mouse liver were also used for testing the DLE sera.

Fifty four per cent of patients with DLE had positive ANAs on one or more substrate but only $20 \%$ on mouse liver alone. The cell lines had different sensitivities. The maximal yield with one substrate alone was with $\mathrm{HEp}_{2}$ cells $(45 \%)$, while T47D cells detected $37 \%$. The human keratinocytes were less sensitive, detecting only $22 \%$ and contributing only one positive that was not detected by another substrate. Forty seven per cent of the positive sera showed a speckled pattern which varied little on dilution. The control sera gave no positive results on mouse liver and $17 \%$ positive with $\mathrm{HEp}_{2}$ cells at a titre of $1 / 10$ and $3 \%$ at a titre of $1 / 40$. The patterns were particulate (speckled and thready).

\section{Discussion}

The use of nuclear fluorescent patterns of ANAs as immunological markers for subsets of connective tissue diseases has led to a complex system of classification. ${ }^{9}$ The nuclear fluorescent patterns are described as non-particulate peripheral and homogeneous (diffuse) staining and particulate staining, including speckled, nucleolar, and thready patterns. Disease associated patterns have been reported for speckled (calcinosis, Raynaud's phenomenon, oesophageal dysmotility, sclerodactyly, telangiec- 


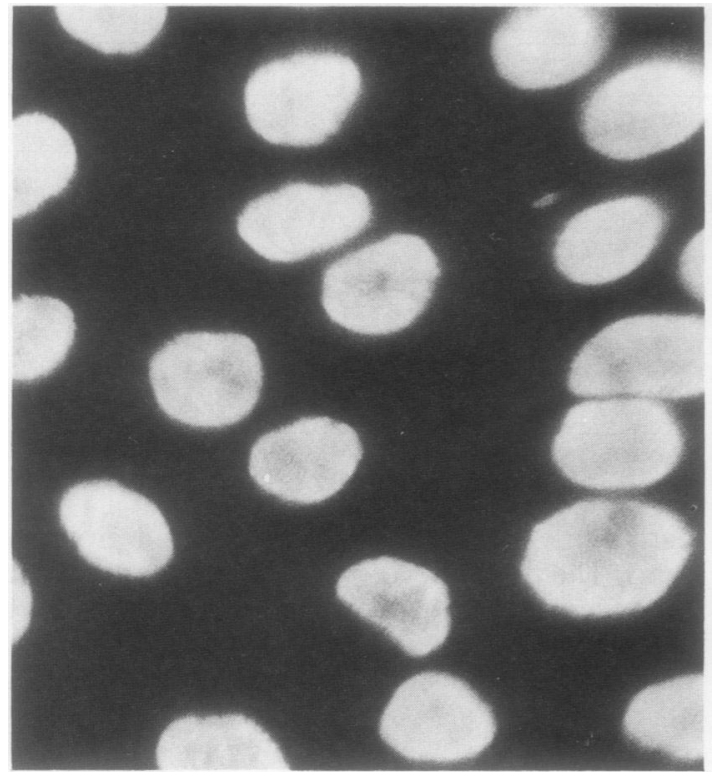

Fig. 1a

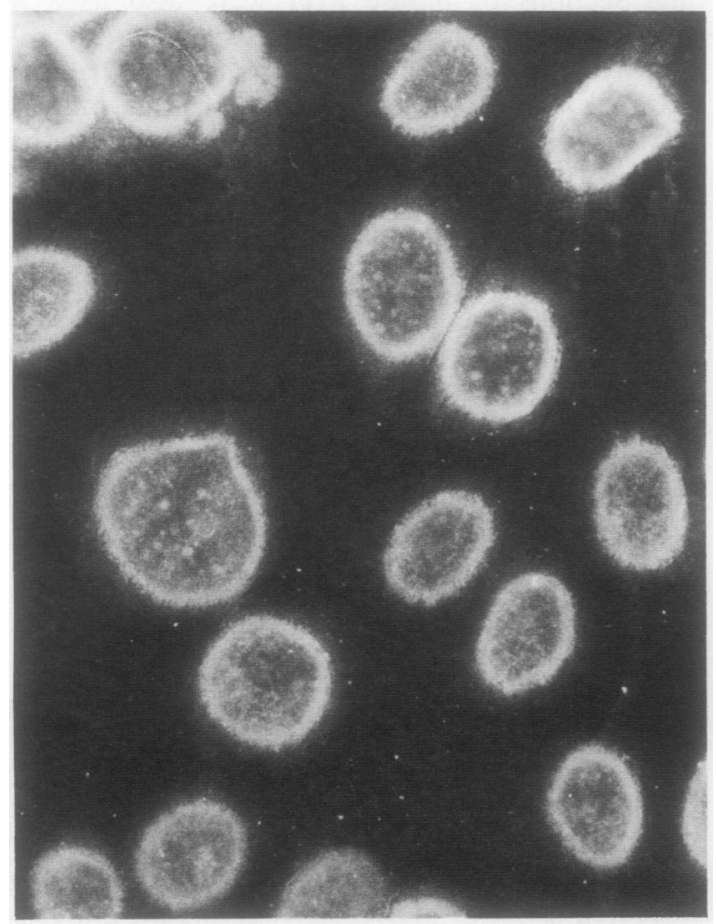

Fig. 1b

Fig. 1 ANA pattern of SvK14 cells. a. Homogeneous. b. Peripheral. c. Speckled. d. Nucleolar (multiple nucleoli).

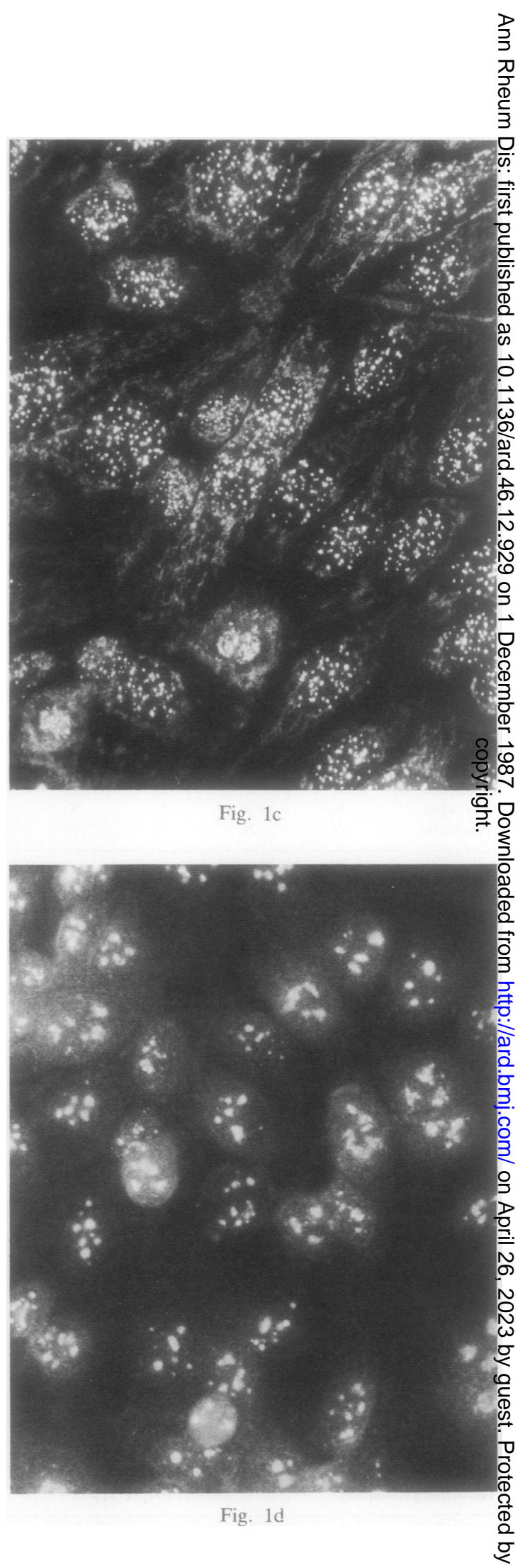


tasia (CREST) syndrome) ${ }^{10}$ and nucleolar (systemic sclerosis) or peripheral (systemic lupus erythematosus). ${ }^{1}$ Indirect immunofluorescent techniques show quantitative and qualitative differences between substrates. ${ }^{11}$ The classical substrate, mouse liver, does not show the same sensitivity as human spleen cells, ${ }^{12}$ presumably because there is species variation in antigen structure or presentation. Cultured cell lines have been used as substances for ANAs to eliminate the problems of tissue variation and to increase sensitivity and reproducibility. Intracellular detail is also easier to detect in the flat spread out nuclei of cell monolayers. In addition, a high percentage of cells divide in culture, and nuclear antigens which are cycle dependent, such as the proliferating cell nuclear antigen, ${ }^{13}$ can be detected more readily.

We have shown that all the human cell lines used were suitable for the detection of ANAs but confirmed that the titre and pattern of ANA staining were markedly substrate dependent. $\mathrm{HEp}_{2}$ cells and T47D were the most sensitive for detection of ANAs in standard sera, T47D showing particularly high expression of peripheral antinuclear staining. A number of different staining patterns were shown by the same sera, confirming that patients may produce autoantibodies to more than one nuclear antigen. ${ }^{1}$ SvK14 cells were more sensitive than primary keratinocytes, which must reflect altered nucleoprotein antigenicity following transformation.

The use of $\mathrm{HEp}_{2}$ and T47D cells as substrates for testing DLE sera increased the number of positive sera compared with mouse liver, but the use of normal human keratinocytes conferred small additional benefit (1/78 positive patients). The number of DLE patients with ANAs was less than in the study of Wermuth et al of DLE/subacute LE, ${ }^{14}$ but this was because we excluded patients with subacute LE. The use of multiple substrates for screening was essential as different substrates detected different positive ANAs. The combined substrates detected positive ANAs in $54 \%$ of patients compared with $20 \%$ on mouse liver alone. There was no correlation between positive ANAs and photosensitivity, chilblains, Raynaud's phenomenon, arthralgia, skin type, or medication (Mayou, unpublished data). Screening of patients with DLE on multiple human cell lines combined with longitudinal studies will be necessary to determine the clinical and prognostic significance of these findings.

The multiple patterns of antibody reactivity found using cell lines may reflect polyclonal B cell stimulation in patients with LE. ${ }^{15}$ Distinct patterns of reactivity on different substrates can be shown by immunodiffusion to be identical antigens, e.g., antiRo and SSA antibodies. ${ }^{16}$ The variation in pattern with substrate emphasises the importance of biochemical characterisation of antigenic sites and the need for molecular biology techniques to clarify the specificity of the patterns. As these techniques become more widely available comparison of different laboratory results will be easier.

\section{References}

1 Sontheimer R D, Deng J S. Gilliam J N. Antinuclear and anticytoplasmic antibodies: concepts and misconceptions. $\mathrm{J} \mathrm{Am}$ Acad Dermatol 1983; 9: 335-43.

2 Moroi Y, Peebles C, Fritzler M J. Steigerwald J, Tan E M. Autoantibody to centromere (kinetochore) in scleroderma sera. Proc Natl Acad Sci USA 1980; 77: 1627-31.

3 Tuffanelli D L, McKeon F, Kleinsmith D' A M, Burnham T K. Kirschner M. Anticentromere and anticentriolar antibodies in the scleroderma spectrum. Arch Dermatol 1983; 119: 560-6.

4 Molden D P, Nakamura R M, Tan E M. Standardisation of the immunofluorescent test for autoantibody to nuclear antigens: use of reference sera of defined specificity. Am J Cut Pathol 1984; 82: 57-66.

5 Norris D A. New evidence pertaining to the mechanism of cutaneous lupus erythematosus. In: MacDonald D M, ed. Immunodermatology. London: Butterworth, 1984.

6 Rheinwald J G, Green H. Serial cultivation of strains of human keratinocytes: the formation of keratinising colonies from single cells. Cell 1975; 6: 331-43.

7 Rook A, Wilkinson D, Ebling G, Rowell N. Textbook of dermatology. 3rd ed. Oxford: Blackwell, 1981.

$8 \mathrm{Wu}$ Y J. Parker L M. Binder N E, et al. The mesothelial keratins: a new family of cytoskeletal proteins identified in cultured mesothelial cells and non-keratinising epithelia. Cell 1982; 31: 693-703.

9 Burnham T K. Antinuclear antibodies-a simplified pattern of nuclear fluorescent patterns. Arch Dermatol 1978; 114: 1343-4.

10 Fritzler M J, Kinsella T D. The CREST syndrome: a distinct serological entity with anticentromere antibodies. Am J Med 1980; 69: 520-6.

11 Cleymaet J E, Nakamura R M. Indirect immunofluorescent antibody tests: comparison of sensitivity and specificity of different substrates. Am J Clin Pathol 1972; 58: 388-93.

12 Maddison P J, Provost T T. Reichlin M. Serological findings in patients with ANA negative systemic lupus erythematosus. Medicine (Baltimore) 1981; 60: 87-94.

13 Miyachi K. Fritzler M J. Tan E M. Autoantibody to a nuclear antigen in proliferating cells. $J$ Immunol 1978; 121: 2228-32.

14 Wermuth D J, Geoghan W D, Jordan R E. Subacute cutaneous lupus erythematosus association with a particulate (large specklelike thread) immunofluorescent nuclear staining. $J$ Invest Dermatol 1984; 121: 335-8.

15 Kind P. Lipsky P E, Sontheimer R D. Circulating T- and B cell abnormalities in cutaneous lupus erythematosus. $J$ Invest Dermatol 1986; 85: 235-40.

16 Allspaugh M, Maddison P. Resolution of identity of certain antigen antibody systems in systemic lupus erythematosus and Sjögren's syndrome: an interlaboratory collaboration. Arthritis Rheum 1979; 22: 796-8.

17 Taylor-Papadimitrou J, Purkis P E, Lane E B, Mackay L A, Chang S E. Effects of SV40 transformation on the cytoskeleton and behavioural properties of human keratinocytes. Cell Differ 1982; 11: $169-80$.

18 Rupniak H T, Rowlat C, Lane E B, et al. Characteristics of four new tumour cell lines derived from squamous cell carcinomas of the head and neck. Journal of the National Cancer Institute 1975; 75: 621-35.

19 Engel L W, Young N A. Human breast carcinoma lines in continuous culture: a review. Cancer Res 1972; 38: 4327-39. 